\title{
The COVID-19 pandemic: A scoping review
}

\author{
Adnan A. Khan*, Shiba Khan*, Unaiza Khan** and Kuntal Das*** \\ Division of Nephrology and Hypertension, Department of Medicine, University of California, San Diego-92121, USA \\ *Emergency Medicine Physician, Hyderabad, Telangana State, India \\ **Senior Registrar, Department of Anaesthesiology, Indraprastha Apollo Hospital, New Delhi-110076, India \\ ***Krupanidhi College of Pharmacy, \#12/1, Chikkabellandur, Carmelaram Post, Varthur Hobli, Bangalore-560035, India
}

\section{Article Info}

\section{Article history}

Received 3 June 2020

Revised 21 June 2020

Accepted 26 June 2020

Published online 30 June 2020

Keywords

COVID-19

Herbal plants

Medication

Pathophysiology

Transmission

Treatment

Vaccine

\begin{abstract}
The entire world is currently under the grip of a pandemic of COVID-19, caused by the novel coronavirus, also known as SARS-CoV2. The virus caused an initial outbreak in Wuhan, China with affected individuals presenting with viral pneumonia. Early on, in the outbreak, metagenomic RNA sequencing shed light on this novel coronavirus which is an enveloped virus, containing a single stranded RNA and gets it name from the crown like spikes on their surface. With limited availability of antivirals at the beginning of the pandemic and no vaccine; a lot of medications were initially re-purposed to treat COVID-19. As more clinical studies continue to be done, and the availability of antivirals increase, there is a huge need to consider alternative ways and means to boost one's immune system along with preventive measures of social distancing, masking and isolation of infected individuals. Natural plant-based products with medicinal properties along with increased exercise and meditation to relax and de-stress, are vital resources that should be overlooked.
\end{abstract}

\section{Introduction}

COVID-19 has resulted in a 'once-in-a-century pandemic' with about 8 million cases and more than 400,000 deaths globally by mid-June 2020. COVID-19 is the disease, caused by SARS-CoV2 virus. It started with a cluster of patients presenting with 'pneumonia of unknown cause' in the Wuhan province of China (Novel coronavirus, 2020). Epidemiologic investigation revealed a common link-which was exposure of all of these affected patients to the Huanan Seafood Market. Analysis of samples from three of these patients suffering from pneumonia and admitted in the Wuhan Jinyintan Hospital resulted in the isolation of SARS-CoV-2 virus from the bronchoalveolar lavage fluid on December 30, 2019 (Zhu et al., 2020). Since then, this novel coronavirus has exponentially spread to 188 more countries, causing widespread morbidity and mortality (Johns Hopkins University, 2020).

\section{History of pandemics}

A pandemic has been historically described as an outbreak of a disease occurring over a wide geographic area (spanning countries) and affecting a significantly high proportion of people.

In the last century, the world has seen few pandemics and its associated mortality (https:/www.euro.who.int/en/health-topics/ communicable-diseases/influenza/pandemic-influenza/pastpandemics. Accessed 20th June, 2020).

Corresponding author: Dr. Adnan A. Khan Suite Plaza 1, 4510 Execute Drive, San Diego-92121, USA E-mail: khan.dr.adnan@gmail.com

Copyright (C) 2020 Ukaaz Publications. All rights reserved.

Email: ukaaz@yahoo.com; Website: www.ukaazpublications.com

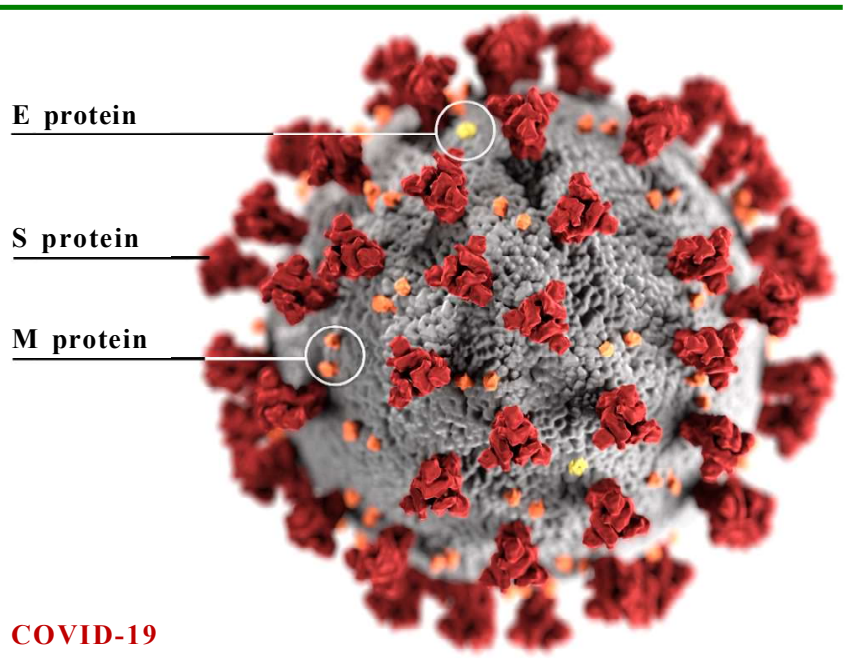

Corona virus - Photo credit: CDC/Alissa Eckert, MS; Dan Higgins, MAMS.

- Spanish flu (H1N1-influenza virus) in 1918-1919 causing about 20-50 million deaths.

- Asian flu (H2N2-influenza virus) in 1957-1958 causing about 1-4 million deaths.

- Hong Kong flu (H3 N2-influenza virus) in 1968 causing about 1-4 million deaths.

- HIV/AIDS as described by some as pandemic and by WHO as a global epidemic, started with the first case in the Democratic Republic of Congo in 1976 and since then has affected more than 37.9 million people with about 770,000 deaths in 2018 from HIV related illnesses. 
With the turn of the $21^{\text {st }}$ century, the influenza (H1N1 virus) pandemic also known as the 'Swine Flu' started in 2009 and resulted in about 18,500 laboratory confirmed deaths; but experts estimate that about 200,000 respiratory deaths and about 80,000 cardiovascular deaths were related to this (Dawood et al., 2012). Again about 10 years after this pandemic, we are now facing COVID-19, a pandemic which continues to cause unimaginable losses.

\section{SARS-CoV2}

SARS-CoV2 is the virus responsible for COVID-19. It is an enveloped single stranded RNA virus that belongs to the coronavirus family; which has four genera: (i) Alpha-coronavirus (alphaCoV), (ii) Betacoronavirus (betaCoV), (iii) Delta-coronavirus (deltaCoV) and (iv) Gamma-coronavirus (gammaCoV). Of these the Alpha and Beta coronaviruses cause human infections (Weiss and Leibowitz, 2011). The severe acute respiratory syndrome virus (SARS-CoV) virus, SARS-CoV2 virus and the Middle East Respiratory Syndrome (MERS-CoV) virus belong to the Beta coronavirus (beta CoV) genera. Coronaviruses usually target and affect the respiratory tracts of birds and mammals. In general, animals act as reservoirs for these viruses with an occasional spillover of infection into humans. Intermediary hosts form the missing link between humans and the reservoirs. In humans, the coronaviruses can cause respiratory infections ranging from a simple common cold to serious infections causing severe acute respiratory illness, including fever, cough, and shortness of breath as seen in people suffering with Severe Acute Respiratory Distress (SARS) and Middle East Respiratory Syndrome.

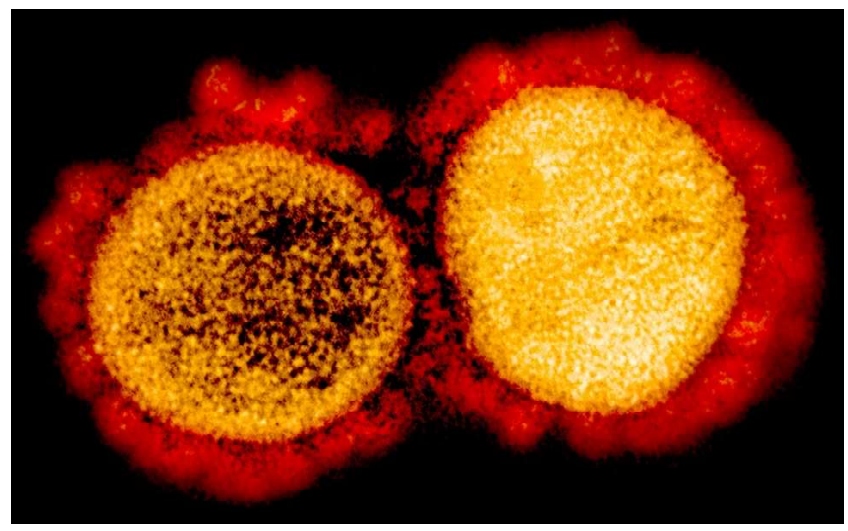

Transmission electron micrograph of SARS-CoV-2 virus particles, isolated from a patient. Image captured and color-enhanced at the NIAID Integrated Research Facility (IRF) in Fort Detrick, Maryland. Photo Credit: NIAID

\section{Severe Acute Respiratory Syndrome (SARS)}

The severe acute respiratory syndrome also known as SARS emerged in China in Nov 2002 with the outbreak rapidly spreading and resulting in about 8000 cases and an estimated 800 deaths. Cases of SARS was reported in about 26 countries and the outbreak was controlled by epidemiological surveillance, identification, and isolation of patients, contact tracing and quarantining of contacts, thereby interrupting person-to-person transmission of the virus. The outbreath was eventually brought under control by July, 2003 (Wilder-Smith et al., 2020).

\section{Middle Eastern Respiratory Virus (MERS)}

Middle Eastern Respiratory Virus first emerged in Saudi Arabia in June 2012, when the fist patient died of pneumonia and renal failure. The virus which was novel for that time was identified as Middle Eastern Respiratory Virus (Wit et al., 2016). Thereafter, cluster outbreaks have been reported with cases in over 27 countries. By January 2020 as per WHO estimates, about 2500 cases with more than 800 deaths from MERS have been reported (MERS situation update, 2020).

\section{Evolutionary origin}

In regard to the evolutionary origin of SARS-CoV2, phylogenetic analysis suggests a zoonotic origin with bats likely being the natural hosts (Vijaykrishna et al., 2007; Li, 2005). This is based of years of intense scientific effort focused on identifying the zoonotic source of the coronavirus, starting at the time of the SARS epidemic in 2003 and continuing through the MERS epidemic in 2012. Initial genomic analysis done by the China Novel Coronavirus Investigating and Research Team confirmed the same and showed that SARSCoV2 virus was about $85 \%$ close to the bat SARS-like CoV(bat-SLCoVZC45) in identity. It is thought that these coronaviruses may not have been transmitted to humans from bats directly but likely through intermediary hosts. Dromedary camels and the palm civets have been identified as potential intermediary hosts for SARS-CoV and the MERS virus. For SARS-CoV2, the intermediary host is so far not certainly known, with pangolins being proposed as potential intermediary host.

\section{Transmission of the virus}

SARS-CoV2 is known to spread primarily from person-to-person. Epidemiological analysis of transmission found that at the onset of the pandemic, greater than $50 \%$ of the confirmed cases had exposure to the Huanan South China Seafood Market. Later, after January $1^{\text {st }}, 2020$ in Wuhan this number started decreasing and was less than $10 \%$ indicating that person-to-person transmission among close contacts was now the significant source of rise in the number of COVID-19 cases (Li, 2005; Li et al., 2005; Li et al., 2005; Li et al., 2005).

Human transmission is thought to occur when the virus spreads between people and is known to occur via (respiratory) droplets when the infected person coughs, sneezes, talks loudly, or forcibly exhales. The airborne transmission also can happen to a lesser extent and it is predominantly seen with aerosol generating procedures that happen during patient care. Contact with fomites is also responsible for spread specially when fomites are unintentionally shared between symptomatic person and contact or between asymptomatic person and a contact. Also contributing to the spread is the stability of the virus on plastic and stainless steel for up to 3 days, and in healthcare settings has also been known to be distributed on patients' bed, handrails, floor and computers especially in the intensive care units (ICU's) where the sickest patients with COVID-19 are admitted. SARS-CoV-2 has the potential of feco-oral transmission with SARS-CoV-2 RNA found in feces of infected patients and a recent study also noted that flushing the toilet can also cause aerosolization of the virus (Li et al., 2020). 
Qun Li et al. (2020) examined the initial data on exposures from Wuhan, China and estimated the incubation period to be 5.2 days (95\% CI $4.1-7.0$ days). Further reviewing the case clusters, the initial epidemic growth rate was found to be 0.1 per day, with the doubling time at 7.4 days. During the same analysis, the duration from illness to the time seeking medical care was a mean of 5.8 days for about 45 patients in their group who had illness before January $1^{\text {st }}, 2020$. This was slightly higher compared to a mean of 4.6 days for the period of January $1^{\text {st }}$ to $11^{\text {th }}, 2020$ and this can be partially related to a better understanding of the disease by that time. Mean duration from onset of symptoms to hospitalization initially was 12.5 days decreasing to 9.1 days subsequently (Li et al., 2020). $\mathrm{R}_{0}$ (reproduction number) is the number of secondary cases resulting from a single initial case. For SARS-CoV2, the $\mathrm{R}_{0}$ was found to be 2.2. per the initial study; but an average of 14 studies showed the average $\mathrm{R}_{0}$ to be 3.28 (Li et al., 2020; Liu et al., 2020). In comparison, the $\mathrm{R}_{0}$ for SARS was estimated to be approximately around 3; and the $\mathrm{R}_{0}$ for MERS-CoV 0.45 for the outbreak in Saudi Arabia to 8.1 for the outbreak in South Korea (Bauch et al., 2005; Killerby et al., 2020).

\section{Pathophysiology}

SARS-CoV2 virus enters the host via inoculation and the virus then tries to establish itself in the body of the host. Like the SARS-CoV virus, the primary target of the SARS-CoV2 virus is also the respiratory tract with the virus having high affinity for the angiotensin-converting enzyme type 2 (ACE2) receptors on the alveolar epithelial cells of the lung (Lake, 2020; Hamming et al., 2004). The virus uses $S 1$ subunit of the $S$ protein to bind onto the host cell surface and then uses the S2 subunit to fuse with the cell membrane of the affected cell (Tang et al., 2020). Once inside the cell, the virus goes through the next phase, wherein the RNA of SARS-CoV2 enters the nucleus and initiates replication. Viral proteins are made and new virions are released. The higher transmissibility

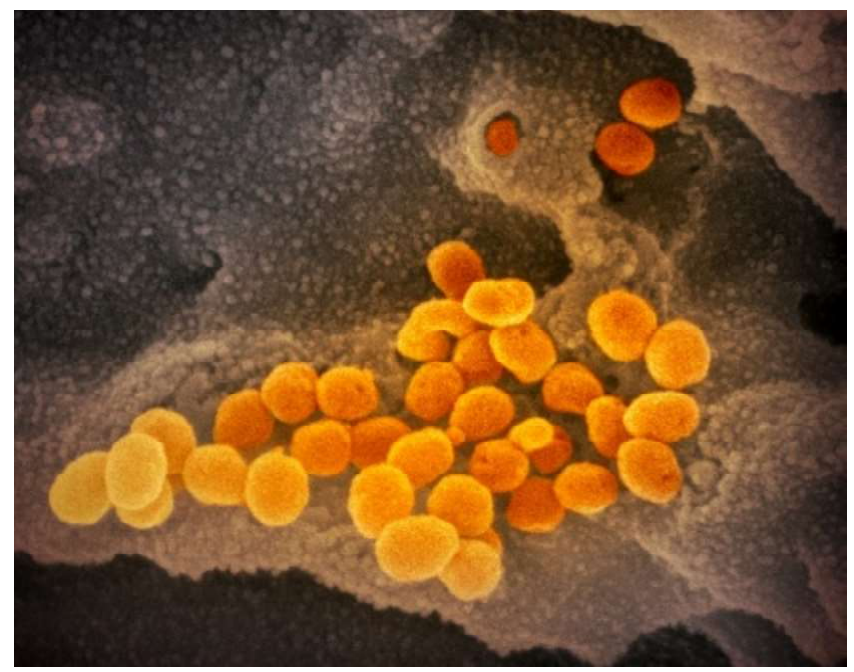

This transmission electron microscope image shows SARS-CoV-2-also known as 2019-nCoV, the virus that causes COVID-19. isolated from a patient in the U.S., emerging from the surface of cells cultured in the lab. Image captured and colorized at NIAID's Rocky Mountain Laboratories (RML) in Hamilton, Montana.

Photo Credit: NIAID of the SARS-CoV2 virus compared to SARS-CoV virus can be explained by its increased affinity of binding to the ACE2 receptor. ACE2 gene expression differs across populations due to gene polymorphisms and is likely the reason for differential susceptibility to SARS-CoV2 infection and some of the geographical differences in severity of COVID-19.

\section{Clinical presentation}

This initial period from the time one gets infected to the development of the symptoms is the incubation period which is known to be about 5 days for the SARS-CoV2 virus. Symptoms start appearing after the incubation period and the most common ones are fever, dry cough, shortness of breath, anosmia (loss of smell), diarrhea, myalgia and/or fatigue (Huang and Wang, 2020). Other symptoms like sputum production, headache, anosmia (loss of smell) and hemoptysis were less frequently seen (Lake, 2020). In a more severe presentation, viral pneumonia develops with worsening shortness of breath, that can progress to acute respiratory distress syndrome (ARDS) with or without multi-organ failure.

Laboratory findings seen in these patients include normal white cell count or leukopenia (decreased white cell count) along with a low lymphocyte count (lymphopenia). In addition, elevated D-dimer, fibrinogen levels, prolong prothrombin time, and elevations in liver enzymes and serum creatinine are seen, indicating acute liver and kidney injury, The lymphopenia seen in COVID-19 is indicative of impaired cellular immunity with a reduction of $\mathrm{T}$ cells, B cells and natural killer (NK) cell. The peripheral blood $\mathrm{T}$ cells were affected the most and this was seen more in the patients with a higher level of sickness. These patients also did have elevated plasma concentrations of proinflammatory mediators and cytokines like IL-2, IL-6, IL-8, IL-10, tumor necrosis factor (TNF)- $\alpha$, granulocyte-colony stimulating factor (G-CSF), monocyte chemoattractant protein 1 (MCP1), macrophage inflammatory protein (MIP) $1 \alpha$ (Tang et al., 2020; Yuki et al., 2020).

Radiological findings in COVID-19 patients mostly include ground glass opacities with diffuse distribution and bilateral lung involvement. Right lower lobe involvement is common and thought to be related to the bronchus being short and straight. CT scan findings early on from Wuhan, China showed that these patients would have progressive worsening of the infiltrates with time. Very early during the period of sub-clinical illness, bilateral ground glass opacities are seen and as disease progresses-a transition from ground glass opacities to consolidation and a reticular pattern with bronchiolectasis happens. Pleural effusion and lymphadenopathy are also seen (Shi et al., 2020).

\section{Testing}

Testing for COVID-19 plays an important role in helping contain the spread of the pandemic by identifying positive cases, that can then be isolated to prevent the spread of disease. Inadequate laboratory testing is a key reason for the continuing spread of COVID-19 in many countries. 


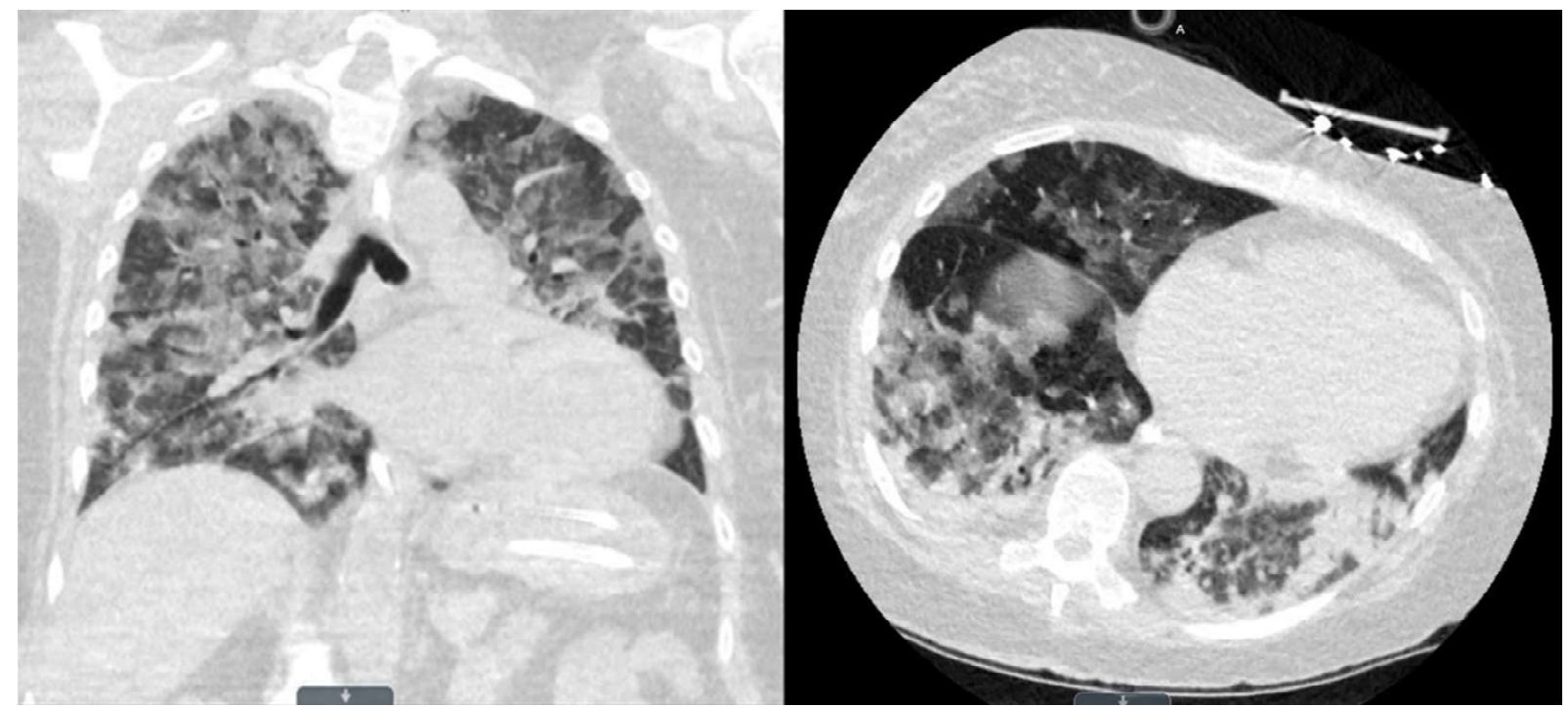

Longitudinal and Transverse CT scan images from a patient with COVID-19.

At the onset of the pandemic, genome sequencing of SARS-CoV2 virus was done at the Shanghai Public Health Clinical Center using metagenomic RNA sequencing of a patients' bronchoalveolar lavage fluid sample. Once the virus was identified, the results were added to a sequence repository, GenBank on January $10^{\text {th }}, 2020(\mathrm{Wu}$ et $a l ., 2020)$. Nucleic acid testing is considered the gold-standard for diagnosing COVID-19. Reverse transcription polymerase chain reaction (RT-PCR) and isothermal amplification are the two most common technologies. RT-PCR kits are designed to detect SARSCoV-2 virus and it works by amplifying a small amount of the genetic material of the virus. Some prominent test kits that have been developed, come from organizations like US Centers for Disease Control and Prevention, Chinese Center For Disease Control and Prevention, Charité Institute of Virology - Germany and Hong Kong University (Udugama et al., 2020; Tang et al., 2020). Rapid point of care testing utilizing the isothermal amplification techniques; can provide results within a short period of time and are also now being used for detection of COVID-19. A new testing method that has recently been available, is the antigen test. Its designed for a rapid detection of the antigen. The specificity of these tests is usually high, but the sensitivity is low, with a higher chance of false negatives compares to RT-PCR tests. Specimen collection for these tests requires a thoughtful approach and site selection to increase the yield and sensitivity/specificity of the tests. Nasopharyngeal (NP) swabs and Oropharyngeal (OP) swabs are recommended due to presence of high viral loads in upper and lower respiratory tracts; with NP swab preferred over the OP swab (Pan et al., 2020; Wölfel et al., 2020; Kim et al., 2011). Other specimens utilized include saliva, sputum, tracheal aspirate and bronchioalveolar lavage.

Serological tests/Antibody tests, are used to detect IgM and IgG antibodies in blood, that would help identify a current or prior infection. These tests are not to be used for testing one's immunity to SARS-CoV2 virus (NIH guidelines). These tests are helpful in identifying cases that were missed by RT-PCR or had a past exposure and recovered; to identify potential convalescent plasma donors.
Seroprevalence data obtained by this form of testing helps understand the prevalence of the disease and in future can be used to assess the response of potential vaccines.

\section{Pre-exposure and post-exposure prophylaxis}

National Institute of Health guidelines for coronavirus DO NOT recommend use of hydroxychloroquine for pre-or post-exposure prophylaxis except in a clinical trial setting (Coronavirus disease 2019 (COVID-19) Treatment Guideline https:/www.covid19 treatmentguidelines.nih.gov, accessed June 25th, 2020).

A randomized, double-blind, placebo-controlled trial showed that high doses of hydroxychloroquine when initiated within 4 days of high or moderate risk exposure did not prevent illness (Boulware et al., 2020).

\section{Treatment}

Treatment strategy can be based on the severity of illness per NIH guidelines:

\section{i. Asymptomatic illness}

These are patients that test positive for SARS-CoV2 (nucleic acid testing or antigen testing) and have no symptoms. It is recommended that these patients self-isolate at home. No further testing or additional treatment is recommended unless the patients' clinical condition deteriorates

\section{ii. Mild illness}

This group includes patients with signs and symptoms like fever, cough, sore throat, malaise, fatigue, myalgias, headache of loss of smell. Again, this subset of patients should be self-isolating themselves and there is no data at the current point to recommend anti-viral therapy for these patients

\section{iii. Moderate illness}

$\mathrm{NIH}$ has defined this group to include patients who present with signs and symptoms of lower respiratory disease with oxygen 
saturations of $\geq 94 \%$ on room air and/or concurrent positive findings on imaging. This subset of patient's would need closer monitoring due to the potential for the rapid decline in their condition. Standard of care hospital management for this group starts by droplet and contact isolation, limiting provider exposure; laboratory tests including complete blood counts, metabolic profile, renal and liver function studies; ECG, imaging study per the institutional protocol and/or inflammatory markers (depending on availability). Anti-viral drugs and immunotherapy can be used for this subset of patients.

\section{iv. Severe illness}

This group includes patient with a greater severity of illness with oxygen saturations $<94 \%$ on room air, a respiratory rate $>30, \mathrm{PaO} 2 /$ FiO2 $<300 \mathrm{mmHg}$, or lung infiltrates $>50 \%$. These patients are at a high risk of further clinical deterioration and potentially needing intubation and mechanical ventilation. Apart from standard of care hospital management as described above for moderate illness, these patients also need oxygen therapy, empiric antibiotics if secondary bacterial infections are suspected, antivirals and/or immune therapy.

\section{v. Critical illness}

This group includes patient with acute respiratory distress syndrome, septic shock, cardiac dysfunction, cytokine storm (from elevated levels of inflammatory cytokines), and/or worsening of patients underlying medical comorbidities. Multiorgan involvement is also seen in this subgroup.

Guidelines for management from NIH for this group includes:

- Use of fit-tested respirators (N95 respirators) or powered airpurifying respirators for health care workers during aerosolgenerating procedures in addition to other personal protective equipment (PPE) (i.e., gloves, gown, and eye protection such as a face shield or safety goggles).

- High-flow nasal cannula (HFNC) oxygen preferred over noninvasive positive pressure ventilation (NIPPV) for acute hypoxemic respiratory failure despite conventional oxygen therapy.

- Consider a trial of awake prone positioning to improve oxygenation for patients with persistent hypoxemia despite increasing supplemental oxygen requirements in whom endotracheal intubation is not otherwise indicated.

- Continued close monitoring for worsening respiratory status and that intubation, if it becomes necessary, be performed by an experienced practitioner in a controlled setting.

- Mechanical ventilation recommendations for COVID-19 patients with acute respiratory distress syndrome (ARDS); recommendation is use low tidal volume (VT) ventilation (VT 4-8 $\mathrm{ml} / \mathrm{kg}$ of predicted body weight) and prone ventilation for 12 to 16 hours per day for patient with refractory hypoxemia despite optimized ventilation.

- Norepinephrine is recommended as the first-choice vasopressor.

- Investigational antiviral agent remdesivir is recommended for treatment of COVID-19 in hospitalized patients with oxygen saturation of $\leq 94 \%$ on room air or those needing supplemental oxygen (AI) along with those on mechanical ventilation or ECMO.

- Dexamethasone (at a dose of $6 \mathrm{mg}$ per day for up to 10 days) in recommended for patients with COVID-19 who are mechanically ventilated and for patients with COVID-19 who require supplemental oxygen. (**Data from RECOVERY TRIAL done in UK supports the use of dexamethasone) (Low-cost dexamethasone reduces death by up to one third in hospitalized patients with severe respiratory complications of COVID-19 https://www.recoverytrial.net/files/recovery_dexamethasone_ statement_160620_v2final.pdf - accessed June 17th, 2020).

- In critically ill patients with acute kidney injury requiring renal replacement therapy, continuous renal replacement therapy (CRRT), if available if preferred over intermittent hemodialysis.

** While there may be some benefit of immunomodulatory therapy and use of extracorporeal membrane oxygenation (ECMO) for refractory hypoxemia routine use of these therapies is still not recommended due to lack of evidence.

** Favipiravir is an oral anti-viral medication that seems to have shown promising preliminary results in patients with COVID19; based on early data from studies done in China, Japan and Russia and is now approved for emergency medical use in India.

** Use of hydroxychloroquine for treatment of COVID-19 is NOT recommended currently in the US or the UK due to clear lack of evidence of any benefit on hospital stay or mortality from its use (Statement from the Chief Investigators of the Randomized Evaluation of COVid-19 thERapY (RECOVERY) Trial on hydroxychloroquine, 5 June 2020 https://www.recoverytrial.net/ files/hcq-recovery-statement-050620-final-002.pdf - accessed June 17th, 2020).

\subsection{Immune-based therapy}

It includes use of COVID-19 convalescent plasma or SARS-CoV-2 immune globulins for the treatment of COVID-19. Although there are some case reports with positive results on the use of convalescent plasma, it is strongly recommended to follow local/regional medical society guidelines for its use.

NIH concludes that there are insufficient data to recommend either for or against the use of the following agents for the treatment of COVID-19:

- Interleukin-1 inhibitors (e.g., anakinra)

- Interleukin-6 inhibitors (e.g., sarilumab, siltuximab, tocilizumab)

** The above treatment section is adapted and modified from National Institute of Health, USA COVID-19 treatment guidelines

\subsection{Therapeutic options}

While we have outlined the current treatment guidance above for COVID-19, the field of therapeutic options for COVID-19 continues to expand with multiple ongoing studies, reviewing potential antivirals like favipiravir, triazavirin, umifenovir, and antiretroviral drugs such as azvudine, ASC09, and darunavir. Other drugs with activity against SARS-CoV2 like carriomycin, suramin sodium, interferon alpha- $2 b$, corticosteroids, fingolimod, leflunomide and various interleukin inhibitors are being studied. The US Food and Drug Administration (FDA) approved the use of chloroquine and hydroxychloroquine under emergency use authorization (EUA) for use in treatment of COVID-19, and this was revoked on June $15^{\text {th }} 2020$ due to lack of any benefits with treatment using hydroxychloroquine. Thereafter, 
favilavir (favipiravir) had been approved by The National Medical Products Administration of China for the treatment of novel coronavirus. Another well-known antiviral remdesivir gained emergency use authorization (EUA) from FDA on May 1, 2020 based on faster time to recovery in some patients.

Development of a vaccine(s) against COVID-19 is challenging as the process that normally takes years will have to be dramatically shortened. Vaccine researchers continue to put in endless efforts towards the discovery of a safe and effective vaccine, with clinical trials ongoing for some and an effort to get the vaccine out as early as possible. More than 140 vaccine candidates are in different stages of development or have been developed and in the clinical trial phase. As per the latest information, more than 125 vaccines have been developed, but have not started trials yet. Furthermore, 10 vaccines are under testing of safety and dosage study and 3 vaccines are started trials on a large for the testing of efficacy. None of the vaccines have received an approval for use against COVID-19 yet (Corum et al., 2020).

Some of the potential vaccine candidates, under various clinical trial phases, are tabulated in Table 1 (Mullard, 2020).

Hence, till the time vaccines become available, one must consider alternative ways and means to boost their immune system along with preventive measures of social distancing, masking, and isolation of infected individuals to fight COVID-19. Natural plant-based products with antiviral properties and immunomodulatory properties with little known side effects can be used in the fight with COVID-19. Natural plant-based medicines are also now approved for and in use in many countries in Africa, along with countries like India, China, Brazil. These products have antiinflammatory, antiviral, and immunomodulatory properties, which may help in initial protection from the virus. There are thousands of medicinal plants available in nature, that would show many health benefits and among them some important Indian plants recommended by AYUSH are listed with their effective active constituents in Table 2.

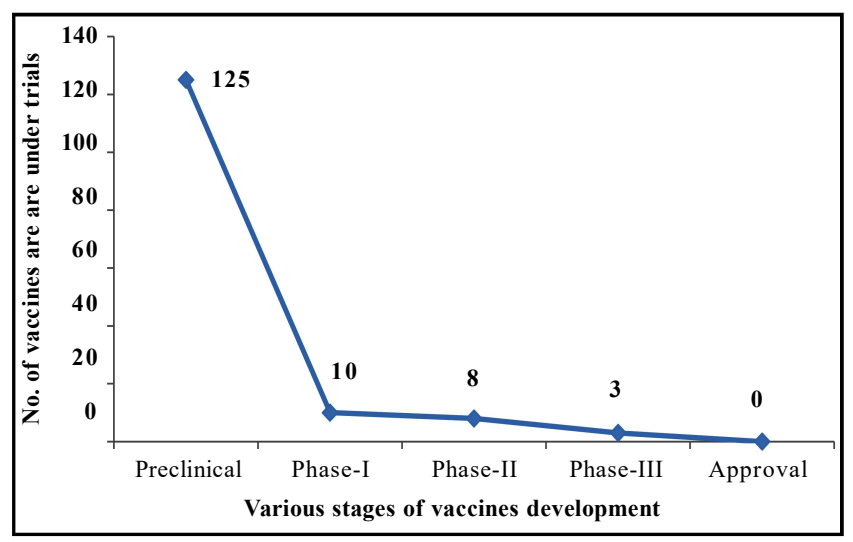

Development of vaccines against deadly COVID-19.

Table 1: Development of various vaccines for the treatment of COVID-19

\begin{tabular}{|l|l|l|l|}
\hline Name of the vaccine & Manufacturer & Properties & Clinical Trial stages \\
\hline mRNA-1273 & Moderna and NIAID & mRNA vaccine & Phase-II \\
\hline BNT162 & BioNTech and Pfizer & mRNA vaccine & Phase-I / II \\
\hline INO-4800 & Inovio Pharmaceuticals & DNA vaccine & Phase-I \\
\hline AZD1222 & University of Oxford and AstraZeneca & Adenovirus vaccine & Phase-IIb/III \\
\hline Ad5-nCoV & CanSino Biologics & Adenovirus vaccine & Phase-II \\
\hline PiCoVacc & Sinovac & Inactivated virus, plus adjuvant & Phase-I/II \\
\hline NVX-CoV2373 & Novavax & Protein subunit & Phase-I/II \\
\hline
\end{tabular}

\section{Implications on research}

COVID-19 has had a huge impact on medical research, among other things. With a surge in cases, shelter in place and/or lockdown followed essentially slowing down business and education thereby impacting revenues. All organizations including healthcare organizations and universities were impacted by this and started bleeding cash. Epicenters of research had to slow down their operations; shut down certain projects, review grant allotments and also in most cases refocus their priorities towards COVID research. Fundraising came to a halt and charity dinners disappeared thereby strapping organization of cash needed to sponsor this research. While research on COVID-19 took off; research in areas like cancer, chronic diseases and heart disease was significantly impacted.

An overwhelming amount of literature started pouring out of countries, impacted the most at the onset of the pandemic. Almost every journal has provided free access to articles on COVID-19 and there have been pre-print servers that have hosted and continue to host, pre-print versions of these articles prior to the peer-review process. This has been very helpful, as the rest of the world was still learning about COVID-19 and a rapid dissemination of information within the scientific community was essentially needed. In an attempt to facilitate this, many medical journals started expediting their peer review process and this rush to get the data out quickly also unintentionally resulted in the dilution of the robust peer review process. The result of this was the publication of articles which would normally have never made through a peer review process. Then there was the issue of preprint servers which worked like a double edged sword - while they helped disseminate information essential to the diagnosis and management of COVID-19, they also hindered the progress in the understanding of COVID-19, by providing misleading information in the form of poorly done studies and/or poorly written articles lacking sound scientific rationale. 
Table 2: Herbal plants with medicinal properties useful for consideration in COVID-19

\begin{tabular}{|c|c|c|c|c|}
\hline Name & Family & Phytoconstituents & Part uses & Main activity \\
\hline Aloe vera (Aloe barbadensis miller) & Liliaceae & Aloe polysaccharides & Leaves & $\begin{array}{l}\text { Antiviral } \\
\text { Anti-inflammatory }\end{array}$ \\
\hline Ashwagandha (Withania somnifera) & Solanaceae & Withaferin & Roots & Immunomodulator \\
\hline Black pepper (Piper nigrum) & Piperaceae & Piperine & Fruits & $\begin{array}{l}\text { Anti-inflammatory } \\
\text { Antiviral }\end{array}$ \\
\hline Edible amaranth (Amaranthus tricolor) & Amaranthaceae & Fatty acids, sterols & Leaves, Flowers & Antiviral \\
\hline Fenugreek (Trigonella foenum-graecum) & Fabaceae & Sterols & Seeds & Anti-inflammatory \\
\hline Garlic (Allium sativum) & Amaryllidaceae & Allicin, Diallyl trisulfide, Ajoene & Bulb & $\begin{array}{l}\text { Antiviral } \\
\text { Immunomodulator } \\
\text { Anti-inflammatory }\end{array}$ \\
\hline Ginger (Zingiber officinale) & Zingiberaceae & Gingerol & Rhizome & $\begin{array}{l}\text { Antiviral } \\
\text { Immunomodulator } \\
\text { Anti-inflammatory }\end{array}$ \\
\hline Green tea (Camellia sinensis) & Theaceae & Kaempferol 3-O-beta-D-glucopyranoside & Leaves & $\begin{array}{l}\text { Antiviral } \\
\text { Immunomodulator }\end{array}$ \\
\hline Guduchi (Tinospora cordifolia) & Menispermaceae & Cordifolioside-A, Tinosporin & Leaves & $\begin{array}{l}\text { Antiviral } \\
\text { Immunomodulator }\end{array}$ \\
\hline $\begin{array}{l}\text { Indian Gooseberry-Amla (Phyllanthus } \\
\text { emblica) }\end{array}$ & Phyllanthaceae & $\begin{array}{l}\text { (2S)-Eriodictyol 7-O-(63 -O-galloyl)- } \\
\text { beta-D-glucopyranoside }\end{array}$ & Fruits & $\begin{array}{l}\text { Antiviral } \\
\text { Immunomodulator }\end{array}$ \\
\hline Liquorice (Glycyrrhiza glabra) & Leguminosae & Glycyrrhizin & Roots and stolon & $\begin{array}{l}\text { Antiviral } \\
\text { Immunomodulator } \\
\text { Anti-inflammatory }\end{array}$ \\
\hline Neem (Azadirachta indica) & Meliaceae & Azadirachtin & Leaves & $\begin{array}{l}\text { Antiviral } \\
\text { Immunomodulator } \\
\text { Anti-inflammatory }\end{array}$ \\
\hline Picrorrhiza (Picrorhiza kurroa) & Scrophulariaceae & Picroside I, Kutkoside, Androsin & Rhizome & $\begin{array}{l}\text { Antiviral } \\
\text { Immunomodulator } \\
\text { Anti-inflammatory }\end{array}$ \\
\hline Tulsi (Ocimum sanctum) & Labitaceae & Oleanolic acid, Ursolic acid, Eugenol & Rhizome & $\begin{array}{l}\text { Antiviral } \\
\text { Immunomodulator }\end{array}$ \\
\hline Turmeric (Curcuma longa) & Zingiberaceae & Curcumin & Rhizome & $\begin{array}{l}\text { Antiviral } \\
\text { Immunomodulator }\end{array}$ \\
\hline
\end{tabular}

There are a few examples which exemplify this. Three studies on COVID-19 done by researchers using Surgisphere Corporations database have been retracted now from two of the world most prominent journals-one of them each from New England Journal of Medicine and another from The Lancet. The Lancet was also highly critical of Surgisphere corporation's lack of scientific integrity and recommended urgent institutional reviews of Surgipsphere's research collaboration. On similar lines another incidence of a failure in peer review process includes the publication of a study by Goutret et al. in International Journal of Antimicrobial Agents, which the journal agreed did not meet the society's expected standard. All the above-mentioned articles have had a significant impact, as they promoted or rejected a certain therapy, without enough scientific evidence, thereby placing public life in danger.

\section{Conclusion}

COVID-19 is a 'once in a lifetime' pandemic, that has impacted hundreds of countries around the world causing significant loss of property and life. The world continues to wage a battle against an invisible enemy and this battle can only be won with the help of science and the use of scientifically proven therapies.

\section{Conflict of interest}

The authors declare that there are no conflicts of interest relevant to this article.

\section{References}

Accessed (20th June, 2020). https://www.euro.who.int/en/health-topics/ communicable-diseases/influenza/pandemic-influenza/past-pandemics.

Bauch, C.T.; Lloyd-Smith, J.O.; Coffee, M.P. and Galvani, A.P. (2005). Dynamically modeling SARS and other newly emerging respiratory illnesses. Epidemiology, 16(6):791-801. doi: 10.1097/01.ede.0000181633.80269.4c.

Boulware, D. R.; Pullen, M. F.; Bangdiwala, A. S.; Pastick, K. A.; Lofgren, S. M.; Okafor, E. C. and Hullsiek, K. H. (2020). A randomized trial of hydroxychloroquine as postexposure prophylaxis for Covid-19. New England Journal of Medicine. doi: 10.1056/nejmoa2016638

Coronavirus disease 2019 (COVID-19). Treatment Guideline. https:// www.covid19treatmentguidelines.nih.gov, accessed June $25^{\text {th }}, 2020$

Corum, J.; Grady, D.; Wee, S.L. and Zimmer, C. (2020). Coronavirus vaccine Tracker. The New Work Times. Updated on 26th June, 2020. 
Dawood, F.S.; Iuliano, A.D. and Reed, C. (2012). Estimated global mortality associated with the first 12 months of 2009 pandemic influenza A H1N1 virus circulation: A modelling study. The Lancet Infectious Diseases, 12(9):687-695. doi: 10.1016/s1473-3099(12)70121-4.

Hamming, I.; Timens, W.; Bulthuis, M.; Lely, A.; Navis, G. and Goor, H.V. (2004). Tissue distribution of ACE2 protein, the functional receptor for SARS coronavirus. A first step in understanding SARS pathogenesis. The Journal of Pathology, 203(2):631-637. doi: 10.1002/ path. 1570 .

Huang, C.; Wang, Y. and Li, X. (2020). Clinical features of patients infected with 2019 novel coronavirus in Wuhan, China. The Lancet, 395(10223):497-506. doi: 10.1016/s0140-6736(20)30183-5.

Johns Hopkins University and Medicine-Coronavirus Resource Center. https://coronavirus.jhu.edu/map.html, accessed 18th June, 2020

Killerby, M.E.; Biggs, H.M.; Midgley, C.M.; Gerber, S.I. and Watson, J.T. (2020). Middle East respiratory syndrome Coronavirus Transmission. Emerging Infectious Diseases, 26(2):191-198. doi: 10.3201/ eid2602.190697.

Kim, C.; Ahmed, J.A. and Eidex, R.B. (2011). Comparison of nasopharyngeal and oropharyngeal swabs for the diagnosis of eight respiratory viruses by real-time reverse transcription-PCR Assays. PLoS ONE, 6(6). doi: 10.1371/journal.pone.0021610

Lake, M.A. (2020). What we know so far: COVID-19 current clinical knowledge and research. Clinical Medicine, 20(2):124-127. doi: 10.7861/clinmed.2019-coron.

Li, Q.; Guan, X. and Wu, P. (2020). Early transmission dynamics in Wuhan, China, of Novel Coronavirus-Infected Pneumonia. New England Journal of Medicine, 382(13):1199-1207. doi: 10.1056/nejmoa2001316.

Li, W. (2005). Bats are natural reservoirs of SARS-Like Coronaviruses. Science, 310(5748):676-679. doi: 10.1126/science.1118391

Li, W. (2005). Early transmission dynamics in Wuhan, China, of Novel Coronavirus-Infected Pneumonia. List of authors: Qun Li, M.Med., Xuhua Guan, Ph.D., Peng Wu, Ph.D., Xiaoye Wang, M.P.H., Lei Zhou, M.Med., Yeqing Tong, Ph.D., Ruiqi Ren, M.Med., Kathy S.M. Leung, Ph.D., Eric H.Y. Lau, Ph.D., Jessica Y. Wong, Ph.D., Xuesen Xing, Ph.D., Nijuan Xiang, M.Med. et al. Science, 310(5748):676-679. doi: 10.1126/science.1118391.

Li, W.; Chan, J.F.; Yuan, S. and Kok, K.H. (2005, 2020). A familial cluster of pneumonia associated with the 2019 novel coronavirus indicating person-to-person transmission: A study of a family cluster. Lancet, 395(10223):514-523. Science, 310(5748):676-679. doi: 10.1126/ science.1118391.

Li, W.; Huang, C.; Wang, Y.; and Li, X. (2005, 2020). Clinical features of patients infected with 2019 novel coronavirus in Wuhan, China. Lancet, 395(10223):497-506. Science, 310(5748):676-679. doi: 10.1126/science. 1118391 .

Li, W.; Li, Q.; Guan, X. and Wu, P. (2005, 2020). Early transmission dynamics in Wuhan, China, of novel coronavirus-infected pneumonia. N. Engl. J. Med., 382(13):1199-207. Science, 310(5748):676-679. doi: $10.1126 /$ science. 1118391 .

Li, Y.Y.; Wang, J.X. and Chen, X. (2020). Can a toilet promote virus transmission? From a fluid dynamics perspective. Physics of Fluids, 32(6):065107. doi: 10.1063/5.0013318.
Liu, Y.; Gayle, A.A.; Wilder-Smith, A. and Rocklöv, J. (2020). The reproductive number of COVID-19 is higher compared to SARS coronavirus. Journal of Travel Medicine, 27(2). doi: 10.1093/jtm/taaa021.

Low-cost dexamethasone reduces death by up to one third in hospitalized patients with severe respiratory complications of COVID-19 https:// www.recoverytrial.net/files/recovery_dexamethasone_statement_ 160620_v2final.pdf - accessed June 17th, 2020

MERS situation update (2020). World Health Organization (2020). http:// www.emro.who.int/health-topics/mers-cov/mers-outbreaks.html, accessed June 22, 2020.

Mullard, A. (2020). COVID-19 vaccine development pipeline gears up. The Lancet, 395:1751-1752.

Novel coronavirus-China (2020). http://www.who.int/csr/don/12-january2020-novel-coronavirus-china/en/ (Jan 12, 2020), Accessed 14th Jun 2020.

Pan, Y.; Zhang, D.; Yang, P.; Poon, L.L.M. and Wang, Q. (2020). Viral load of SARS-CoV-2 in clinical samples. The Lancet Infectious Diseases, 20(4):411-412. doi :10.1016/s1473-3099(20)30113-4

Qin, C.; Zhou, L. and Hu, Z. (2020). Dysregulation of immune response in patients with Coronavirus 2019 (COVID-19) in Wuhan, China. Clinical Infectious Diseases. doi:10.1093/cid/ciaa248.

Shi, H.; Han, X. and Jiang, N. (2020). Radiological findings from 81 patients with COVID-19 pneumonia in Wuhan, China: A descriptive study. The Lancet Infectious Diseases, 20(4):425-434. doi: 10.1016/ s1473-3099(20)30086-4

Statement from the Chief Investigators of the Randomized Evaluation of COVID-19 THERAPY (RECOVERY) Trial on hydroxychloroquine, 5 June 2020. https://www.recoverytrial.net/files/hcq-recoverystatement-050620-final-002.pdf - accessed June 17th, 2020

Tang, D.; Comish, P. and Kang, R. (2020). The hallmarks of COVID-19 disease. PLOS Pathogens, 16(5). doi: 10.1371/journal.ppat.1008536.

Tang, Y.W.; Schmitz, J.E.; Persing, D.H. and Stratton, C.W. (2020). Laboratory diagnosis of COVID-19: Current issues and challenges. Journal of Clinical Microbiology, 58(6). doi: 10.1128/jcm.00512-20

Udugama, B.; Kadhiresan, P. and Kozlowski, H.N. (2020). Diagnosing COVID19: The disease and tools for detection. ACS Nano, 14(4):38223835. doi: $10.1021 /$ acsnano.0c02624

Vijaykrishna, D.; Smith, G.J.D.; Zhang, J.X.; Peiris, J.S.M.; Chen, H. and Guan, Y. (2007). Evolutionary Insights into the Ecology of Coronaviruses. Journal of Virology, 81(8):4012-4020. doi: 10.1128/jvi.02605-06.

Weiss, S.R. and Leibowitz, J.L. (2011). Coronavirus Pathogenesis. Advances in Virus Research, pp:85-164. doi: 10.1016/b978-0-12-3858856.00009-2.

Wilder-Smith, A.; Chiew, C.J. and Lee, V.J. (2020). Can we contain the COVID19 outbreak with the same measures as for SARS? The Lancet Infectious Diseases, 20(5). doi:10.1016/s1473-3099(20)30129-8.

Wit, E.D., Doremalen, N.V., Falzarano, D. and Munster, V.J. (2016). SARS and MERS: Recent insights into emerging coronaviruses. Nature Reviews Microbiology, 14(8):523-534. doi:10.1038/nrmicro.2016.81.

Wölfel, R.; Corman, V.M. and Guggemos, W. (2020). Virological assessment of hospitalized patients with COVID-2019. Nature, 581(7809):465-469. doi: $10.1038 / \mathrm{s} 41586-020-2196-\mathrm{x}$ 
Wu, F.; Zhao, S. and Yu, B. (2020). A new coronavirus associated with human respiratory disease in China. Nature, 579(7798):265-269. doi: $10.1038 / \mathrm{s} 41586-020-2008-3$

Yuki, K.; Fujiogi, M. and Koutsogiannaki, S. (2020). COVID-19 pathophysiology: A review. Clinical Immunology, 215:108427. doi: $10.1016 /$ j.clim.2020.108427
Zhou, Y.; Fu, B. and Zheng, X. (2020). Pathogenic T-cells and inflammatory monocytes incite inflammatory storms in severe COVID-19 patients. National Science Review, 7(6):998-1002. doi: 10.1093/ nsr/nwaa041

Zhu, N.; Zhang, D. and Wang, W. (2020). A novel coronavirus from patients with pneumonia in China, 2019. New England Journal of Medicine, 382(8):727-733. doi: 10.1056/nejmoa2001017.

Citation: Adnan A. Khan, Shiba Khan, Unaiza Khan and Kuntal Das (2020). The COVID-19 pandemic and its implications on research. Ann. Phytomed., 9(1):18-26. http://dx.doi.org/10.21276/ap.2020.9.1.3 